\title{
Transperineal bilateral sacrospineous colpofixation for the treatment of female genital prolapse -5 -year results
}

\author{
FRANZISKA C. HEMPTENMACHER ${ }^{1}$, (1) STEFAN OLLIG², (1) ANDREAS SÜSSE ${ }^{3}$, (1) DIRK G. KIEBACK ${ }^{1}$ \\ 1Department of Obstetrics and Gyneacology, Ev.-Luth. Diakonissenanstalt Flensburg, Lehrkrankenhaus der Christian-Albrechts-Universität zu Kiel und der \\ Universität zu Lübeck, Germany \\ 2Department of Obstetrics and Gyneacology Diakonissenkrankenhaus Dresden, Dresden, Germany \\ ${ }^{3}$ Department of Obstetrics and Gynaecology HELIOS Klinikum Aue, Aue, Germany
}

\begin{abstract}
Objective: Female genital prolapse is observed with increasing frequency in the era of large aging populations. Various surgical techniques have been established, varying in performance, difficulty and outcome, specifically complications. In order to optimize both aspects, we have developed a refined transperineal bilateral sacrospineous colpofixation technique (TPBCF) and given a detailed, step-by-step description of the technique.

Materials and Methods: In a study of 162 patients with vaginal prolapse surgical and functional outcomes of TPBCF have been evaluated with 5-year follow-up.

Results: No rectal injury was observed re-intervention for any complications was limited to three erosions with only one requiring resection of $2 \mathrm{~cm}$ of tape in the median position followed by successful re-closure. Prolapse correction was found at 5 years to be $61 \%$ POPQ 0 and $39 \%$ POPQ1.

Conclusion: These results were stable when compared with follow-up data at 6 months postoperatively. The authors conclude, that TPBCF is an efficient minimally invasive technique for the treatment of female genital prolapse with a favourable effect/complication ratio.

Keywords: Transperineal bilateral sacrospineous colpofixation; operative therapy; vaginal sling placement; vaginal vault prolapse, surgery, complications, outcome, 5-year results
\end{abstract}

\section{INTRODUCTION}

Female genital prolapse is a known clinical entity observed increasingly frequently in the era of large aging populations. ${ }^{1}$ Historically, treatment options included abdominal surgical interventions such as sacrocolpopexy or fascial slings, 2,3 and operations via the vaginal approach such as the unilateral Amreich-Richter operation with the vaginal apex sutured to the sacral bone after hysterectomy. ${ }^{4}$ More recently, extensive reconstructions using prosthetic mesh for the induction of neo-ligaments and neofasciae have been advocated, ${ }^{5}$ sometimes also in the context of primary surgical interventions in the unpretreated patient. ${ }^{6}$ Intravaginal slings (IVS) placed transischiorectally have been proposed by Farnsworth ${ }^{7}$ and Petros ${ }^{8}$ shown to be promising in a small series of cases. However, rectal injury and erosions were identified as major problems of this technique which led to the abandonment of IVS. ${ }^{9}$ A multi-centre series in Austria yielded better results but still described severe complications. ${ }^{10} \mathrm{~A}$ refined

Address for Correspondence: Dirk Kieback, Department of Obstetrics and Gynaecology, Evangelische Diakonissenanstalt, Knuthstrasse 1, 24939 Flensburg, Germany E-mail: dirkkieback@hotmail.de ORCID ID: orcid.org/0000-0001-8651-9353

Received: 29 January 2020 Accepted: 12 May 2020

(C) Copyright 2020 by the International Society for Pelviperineology / Pelviperineology published by Galenos Publishing House. 
approach to transperineal bilateral sacrospineous colpofixation (TPBCF) utilizing a standardized 12-step procedure was developed ${ }^{11}$. This investigation is based on this surgical strategy.

\section{MATERIALS AND METHODS}

The premanufactured tape used for TPBCF consists of a monofilament microporous braided polypropylene mesh of a weight of $70 \mathrm{~g} / \mathrm{m}^{2}$. It is $1 \mathrm{~cm}$ wide and approximately $40 \mathrm{~cm}$ of this material are implanted during the operation resulting an approximately $2.8 \mathrm{~g}$ of foreign body to remain in the patient. In a prospective study 162 patients were treated by TPBCF at HELIOS Klinikum Aue in an open single centre design. Patients with significant anatomical defects in the median pelvic compartment resulting in various stages of vaginal, utero-vaginal or cervical prolapse were included. Primary and secondary cases were admitted to the trial. There was no patient selection and no other treatment modality for the treatment of prolapse was used for the duration of the study. Vaginal estriol pre-treatmentfor at least two weeks was mandatory. Surgery was performed by three designated surgeons under general or regional anaesthesia following the published method. ${ }^{11}$ Follow-up examinations were performed at 2 weeks, $6^{\text {th }}, 12^{\text {th }}, 24^{\text {th }}$ and $60^{\text {th }}$ months. after surgery.

Results were recorded according to the POPQ scale, complications and quality of life parameters were assessed. Postoperative variables included length of surgery, blood loss, pain and duration of hospital stay. All postoperative examinations and determinations were performed by a single GYN specialist trained as a pelvic floor surgeon, but not otherwise involved in the trial and in no case surgeon of the participating patients.

At the time that the investigation was performed no separate ethics consent was required for routine observational followup studies without additional interventions. Data evaluation consent was given at the time of admission as a standard procedure.

\section{Statistical Analysis}

Differences between frequencies were assessed using distribution-free statistics i.e Fisher's exact test for small sample sizes or the Wilcoxon test for differences of medians. Regression analysis was performed to examine the possible correlation of age, body mass index (BMI), parity, menopausal status, American Society of Anaesthesiologists (ASA), blood loss and previous pelvic floor surgery with the quality of the surgical outcome.

\section{RESULTS}

The median age of participants was 65.8 years [standard deviation $(S D)=10.3] \quad$ (Table 1). Ninety-three percent were postmenopausal, the median BMI was $28(S D=4.1)$ with parity at 2.13 (Table 2, 2a, 2b) (SD=0.98). 8\% of the patients were classified as ASA 1, 75\% as ASA 2, 17\% as ASA 3. (Table 3) 127 patients had undergone surgeries relevant to the pelvic floor before presenting for treatment in this study (Table 4).

TPBCF was performed preserving the uterus or in combination with hysterectomy in 105 women (64.8\%), anterior colporrhaphy

\section{Table 1. Age distribution}

\begin{tabular}{|l|l|l|l|l|l|l|}
\hline & $\mathbf{n}$ & Median & SD & Spread & Youngest & Oldest \\
\hline Age & 162 & 65.81 & 10.34 & 58 & 30 & 88 \\
\hline \multicolumn{7}{|l|}{ n: Number, SD: Standard deviation } \\
\hline
\end{tabular}

Table 2. Patient characteristics

\begin{tabular}{|l|l|l|l|l|l|l|}
\hline & $\mathbf{n}$ & Median & SD & Spread & Youngest & Oldest \\
\hline Height & 162 & 1.611 & 0.0613 & 0.3 & 1.5 & 1.8 \\
\hline Weight, kg & 162 & 72.78 & 11.553 & 63 & 46 & 109 \\
\hline BMI & 162 & 28.035 & 4.1083 & 23.3 & 17.7 & 41 \\
\hline Parity & 161 & 2.13 & 0.988 & 6 & 0 & 6 \\
\hline \multicolumn{7}{|l|}{ n: Number, SD: Standard deviation, BMI: Body mass index } \\
\hline
\end{tabular}

\section{Table 2a. BMI Distribution}

\begin{tabular}{|l|l|l|}
\hline BMI & $\mathbf{n}$ & Percent \\
\hline $\mathbf{1 7 . 5}$ bis $\mathbf{2 4 . 9}$ & 36 & $22.20 \%$ \\
\hline $\mathbf{2 5}$ & 126 & $77.80 \%$ \\
\hline BMI: Body mass index, n: Number & \\
\end{tabular}

\section{Table 2b. Parity}

\begin{tabular}{|l|l|l|}
\hline Births & n & Prozent \\
\hline No children & 1 & $0.60 \%$ \\
\hline $1-2$ children & 113 & $69.80 \&$ \\
\hline $1-4$ children & 45 & $27.80 \&$ \\
\hline 5 or more children & 2 & $1.20 \%$ \\
\hline n: Number & & \\
\hline
\end{tabular}

Table 3. ASA status of study patients

\begin{tabular}{|l|l|l|l|}
\hline & $\mathbf{n}$ & Percent & Defiinition \\
\hline ASA 1 & 11 & $6.80 \%$ & Healthy patient \\
\hline ASA 2 & 122 & $75.30 \%$ & Illness without physical limitations \\
\hline ASA 3 & 28 & $17.30 \%$ & Severe illness with physical limitations \\
\hline ASA 4 & 0 & 0 & Life-threatening illness \\
\hline \multicolumn{4}{|l}{ ASA: American Society of Anaesthesiologists } \\
\hline
\end{tabular}




\begin{tabular}{|l|l|l|}
\hline Table 4. Surgical pretreatment before entering the study \\
\hline Previous surgery & n & Percent \\
\hline Hysterectomy & 56 & $34.60 \%$ \\
\hline Colpopexy & 3 & $1.90 \%$ \\
\hline Anterior colporrhaphy & 24 & $14.80 \%$ \\
\hline Posterior colporrhaphy & 20 & $12.30 \%$ \\
\hline Cervical conisation & 2 & $1.20 \%$ \\
\hline TVT & 22 & $13.60 \%$ \\
\hline TVT: Tension-free vaginal tape, n: Number & & \\
\hline
\end{tabular}

\begin{tabular}{|l|l|l|}
\hline \multicolumn{4}{|l|}{ Table 5. Surgical procedure on study } \\
\hline Surgical procedure & $\mathbf{n}$ & Percent \\
\hline TPBCF & 162 & $100 \%$ \\
\hline Hysterectomy & 105 & $64.80 \%$ \\
\hline Anterior colporrhaphy & 114 & $70.40 \%$ \\
\hline Posterior colporrhaphy & 46 & $28.40 \%$ \\
\hline Combined colporrhaphies & 31 & $19.10 \%$ \\
\hline TVT & 5 & $3.10 \%$ \\
\hline Other procedures & 1 & $0.06 \%$ \\
\hline TVT: Tension-free vaginal tape, n: Number & & \\
\hline
\end{tabular}

\begin{tabular}{|l|l|l|l|l|l|}
\hline \multicolumn{2}{|l}{ Table 6. Postoperative complaints } \\
\hline Symptoms & Postoperative & $\begin{array}{l}\text { Post } \\
\mathbf{1 4 d}\end{array}$ & $\begin{array}{l}\text { Post } \\
\mathbf{6 m}\end{array}$ & $\begin{array}{l}\text { Post } \\
\mathbf{1 2 m}\end{array}$ & $\begin{array}{l}\text { Post } \\
\mathbf{2 4 m}\end{array}$ \\
\hline Dysuria & 1 & 1 & 2 & 0 & 0 \\
\hline Dyspareunia & 0 & 0 & 1 & 0 & 0 \\
\hline Constipation & 14 & 7 & 2 & 1 & 1 \\
\hline Cystitis & 6 & 4 & 4 & 1 & 1 \\
\hline
\end{tabular}

in 114 patients (70.4\%) or posterior colporrhaphy in $46(28.4 \%)$ (Table 5).

When only TPBCF was performed $(n=6)$, median operating time was 47 minutes (range: 30-83) and median blood loss was found to be $67 \mathrm{~mL}$ (range: 20-200). In combined interventions i.e. together with colporrhaphy, the intervention lasted 82 minutes (range: 40-170). During the course of the hospitalization of 3.07 days (1-6) only 58 patients (35.8\%) reported any pain at all with those with pain ranking its intensity at 1.81 (1-6) on a visual analogue scale of 1-10.

No postoperative infections of the surgical field or hematomas in need of re-intervention were observed. Subcutaneous suggillations of the buttocks were present in $13.6 \%(n=22)$ and resolved spontaneously without treatment. Postoperative complaints are listed in Table 6. The preoperative POPQ distribution is shown in Figure 1. Ninety-two percent of the patients were found to have a POPQ of 1 or better after 6 months
(Figure 2), 88\% after 12 months, and all patients presenting for examination after 60 months. Figure 3 shows the POPQ distribution after 24 months. Treatment efficacy during followup is shown in Figure 4.

Ninety percent of patients subjectively classified the surgical result as good or very good after 1 year. Only one patient reported new onset of dyspareunia.

After 6 months, three patients presented with erosions (1.9\%). Two of those were minimal and resolved without treatment, one patient had a $2 \mathrm{~cm}$ median segment of tape resected with subsequent primary wound healing. Sixty-one patients followed the invitation for a follow-up examination after 60 months (38\%) with an additional 20 (12\%) making themselves available for a telephone interview assessing patient satisfaction and the necessity for interim surgical intervention for recurrent prolapse. Seven patients

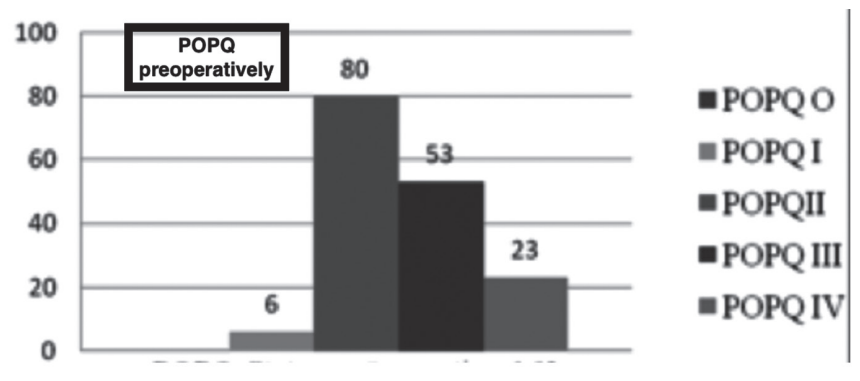

Figure 1. Preoperative POPQ

POPQ: Pelvic Organ prolapse quantifications system

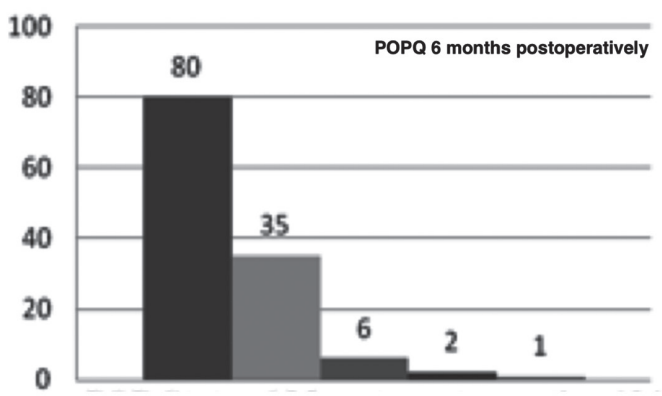

- POPQO

- POPQ I

- POPQII

Figure 2. Postoperative POPQ at 6 Months

POPQ: Pelvic Organ prolapse quantifications system

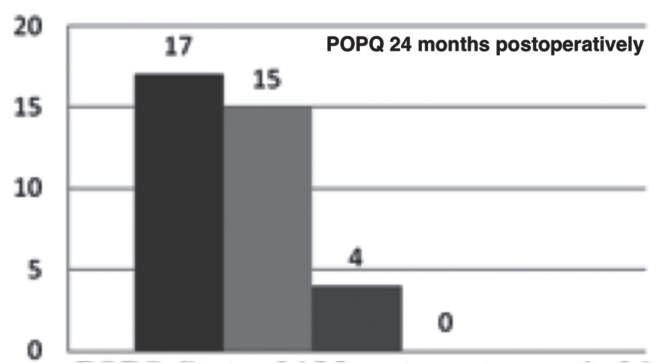

- POPQO - POPQI

- POPQII

-POPQ III

- POPQIV

Figure 3. Postoperative POPQ at 24 Months POPQ: Pelvic Organ prolapse quantifications system 


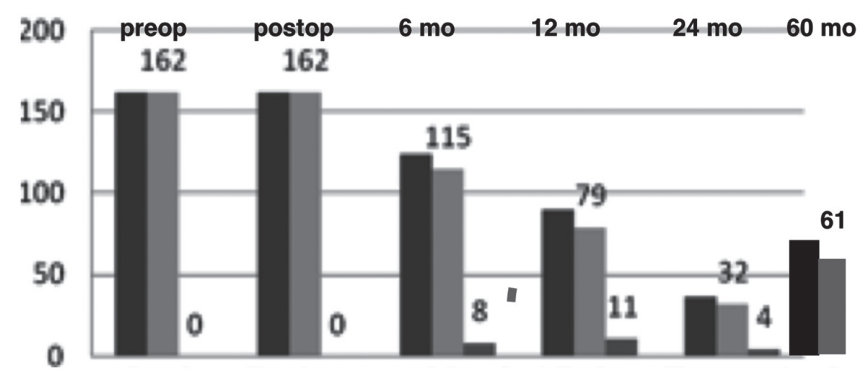

Figure 4. Treatment Success (black and grey bars) determined during follow-up

(4.3\%) had died from other causes during the follow-up interval. There was no significant difference in POPQ compared to the result at 6 months $(p>0.2)$. At five years 56 patients (92\%) were found to have some degree of cystocele with only 13 (21\%) newly developed. In those 13 individuals' cystoceles 54\% were grade I and $46 \%$ grade II.

More pronounced cystoceles grade III (23\%) and IV (3\%) were only observed in the remaining 43 patients. All of the patients with recurrent anterior defects had been undergoing an anterior colporrhaphy at the time of the TPBCF five years prior. Some degree of rectocele was present in 32 patients (52\%). Patient satisfaction was assessed in analogy to German classroom grades ranging from 1 to 6 with 1 being the best. The patients presenting for examination graded their satisfaction with surgical result at five years at 1.6 (range: 1-5), those interviewed by phone at 2.0 (range: 1-6). Seventy-seven percent of all patients assessed at five years ranked their quality of life equal or better than before the surgery.

\section{DISCUSSION}

Fascia lata slings and suspension procedures using the round ligaments have been abandoned as have resorbable meshes due to the fact, that the body does not maintain neoligaments without continuing stimulation of fibroblasts on site. Sacrocolpopexy with or without prosthetic mesh interposition should be combined with a Burch procedure for optimal results as shown by the studies of the NIH Pelvic Floor Disease Network. ${ }^{12-14}$ In sum, this amounts to a significant surgical intervention with laparoscopic techniques adding their own spectrum of possible complications due to their transabdominal nature.

Amreich-Richter results are known for their surgery-induced dyspareunia, deep pelvic pain and secondary urinary continence problems $^{15}$ making them unattractive especially for, but not limited to, the younger patient. While having been in clinical use for a long time, systematic studies of this entity are few. Modifications using unilateral or bilateral non-resorbable sutures that serve as fixing strings suspending the vaginal apex at a distance from the sacrum have never been formally evaluated and remain experimental with anecdotal results. Large prosthetic implants as a primary treatment approach for female genital prolapse are meeting with increased scepticism due to their potential for complications. The FDA has recently issued a statement to the effect, that large meshes are contraindicated as primary treatment in such situations. ${ }^{16}$ The principal weakness of the present study lies in the possible selection bias induced by the decline in the number of patients following the invitation for re-examination after five years. In a population with a median age of at least 70.8 years at that time and seven patients already deceased this is not entirely surprising. From today's perspective, a formal standardized quality of life assessment tool should have been included.

Strengths of this trial lie in the comparably large number of patients, the long-term follow-up and the meticulously standardized surgical procedure. The complete absence of patient selection and the assessment of study end points by a noninvolved specialist increase objectivity of the reported outcomes data and their applicability in the routine clinical setting. The TPBCF approach outlined here offers the potential for the generation of an anatomy-analogous support of the vaginal vault or the uterus mimicking the sacrospinous ligaments or creating sacro-vaginal ligaments in its place. The challenge for the surgeon adopting the procedure will be to overcome a possible initial hesitancy when faced with the insertion of the introducer through the perineum, but in our experience the procedure becomes routine quickly. The indication for TPBCF is vaginal vault, vervical or uterine prolapse, it is not designed to correct anterior, posterior or lateral pelvic floor defects.

In this trial, TPBCF has a low complication rate and a very low frequency of erosions at $1.9 \%$. This compares very favourably with FDA-reports of $10 \%$ for larger mesh implants and with the $5.4 \%$ reported for the IVS apical sling by Farnsworth ${ }^{7}$. This technique was the basis for the development of TPBCF. Our data substantiate the superiority of the standardized TPBCF approach in comparison to the older technique. This fact is further illustrated by less blood loss ( $67 \mathrm{~mL}$ vs 110), shorter operating time (47 vs $60 \mathrm{~min}$ ) and the total absence of rectal perforations ( 0 vs $2.2 \%$ ) in this much larger study population ( $n=162$ vs $n=93$ ). Ninety percent of patients experienced at least a five-year anatomical stability of the apical fixation with Farnsworth? reporting an $87 \%$ success rate in short-term follow-up. When compared to FDA reports both studies exhibit a superior risk/hazard ratio with the TPBCF showing the thus far most 
advantageous profile. As a minimally invasive approach with the potential for conservation of the uterus or cervix TGBCF would potentially be applicable to all age groups and also the increasingly frequent elderly patient with significant comorbidities.

\section{CONCLUSION}

The sum of the available data indicates, that the anatomyanalogous fixation of the vagina, cervix or uterus by this approach may have to be viewed and judged differently from the experience with larger meshes and may warrant reconsidering the generalized negative position of regulatory authorities towards pelvic floor prosthetic implants in favour of a more differentiated view.

Building on the long-term success of the TPBCF-concept in the treatment of prolapse and on developments in mesh technology and surgical instruments, a bilateral elastic colposuspension has been developed for the same surgical indications utilizing HexaPro monofilament macroporous mesh at a material weight of $21 \mathrm{~g} / \mathrm{m}^{2}$ and I-Stich fixation in the pelvis. The entire implant weighs $0.054 \mathrm{~g}$ compared to a regular postal stamp at $0.085 \mathrm{~g}$. The surgical method of Bilateral Sacrospineous Colosuspension has recently been formally described in detail and its evaluation is in progress. ${ }^{17}$ The goal of this development is to maintain the high success rate of the TPBCF while further decreasing foreign body load in the organism of the patient and potentially lowering the incidence of complications even further.

\section{DISCLOSURES}

The authors report no conflicts of interest.

\section{ETHICS}

Ethics Committee Approval: At the time that the investigation was performed no separate ethics consent was required for routine observational follow-up studies without additional interventions.

Informed consent: Informed consent was obtained from the patients.

Peer-review: Externally peer-reviewed.

\section{REFERENCES}

1. Wilkins MF, Wu JM. Lifetime risk of surgery for stress urinary incontinence or pelvic organ prolapse. Minerva Ginecol 2017; 69: $171-7$.

2. Takacs EB, Kreder KJ. Sacrocolpopexy, Surgical Technique, Outcomes, and Complications. Curr Urol Rep 2016; 17: 90.

3. Ijland MM, Fischer DC, Kieback DG, McGrath G, Farnsworth B.
Midline intravaginal slingplasty for treatment of urinary stress incontinence, Results of an independent audit up to 2 years after surgery. Int Urogynecol J Pelvic Floor Dysfunct 2005; 16: 447-54.

4. Lantzsch T, Goepel C, Wolters M, Koelbl H, Methfessel HD. Sacrospinous ligament fixation for vaginal vault prolapse. Arch Gynecol Obstet 2001; 265: 21-5.

5. de Ridder D. Should we use meshes in the management of vaginal prolapse? Curr Opin Urol 2008; 18: 377-82.

6. Dias FGF, Dias PHGF, Prudente A, Riccetto C. New strategies to improve results of mesh surgeries for vaginal prolapses repair--an update. Int Braz J Urol 2015; 41: 623-34.

7. Farnsworth BN. Posterior intravaginal slingplasty (infracoccygeal sacropexy) for severe posthysterectomy vaginal vault prolapse--a preliminary report on efficacy and safety. Int Urogynecol J Pelvic Floor Dysfunct 2002; 13: 4-8.

8. Petros PP. Medium-term follow-up of the intravaginal slingplasty operation indicates minimal deterioration of urinary continence with time. Aust NZ J Obstet Gynaecol 1999; 39: 354-6.

9. Feiner B, Jelovsek JE, Maher C. Efficacy and safety of transvaginal mesh kits in the treatment of prolapse of the vaginal apex, $A$ systematic review. BJOG 2009; 116: 15-24.

10. Bjelic-Radisic V, Hartmann G, Abendstein B, Tamussino K, Riss PA. The posterior intravaginal slingplasty operation, Results of the Austrian registry. Eur J Obstet Gynecol Reprod Biol 2009; 144: 88-91.

11. Buerkle B, Ollig S, Kieback DG. Transperineal Bilateral Sacrospineous Colpofixation (TPBCF) for the treatment of vaginal vault prolapse description of a refined method. Pelviperineology 2018; 37: 49-52.

12. Brubaker L, Cundiff GW, Fine P, et al. Abdominal sacrocolpopexy with Burch colposuspension to reduce urinary stress incontinence. N Engl J Med 2006; 354: 1557-66.

13. Barber MD, Brubaker L, Burgio KL, et al. Comparison of 2 transvaginal surgical approaches and perioperative behavioral therapy for apical vaginal prolapse, The OPTIMAL randomized trial. JAMA 2014; 311: 1023-34.

14. Barber MD, Brubaker L, Nygaard I, et al. Defining success after surgery for pelvic organ prolapse. Obstet Gynecol 2009; 114: 600-9.

15. Kraus $P$, Krofta L, Krčmář M, et al. Řešení sestupu tří kompartmentů pomocí syntetického implantátu a sakrospinózní fixace, Kohortová prospektivní studie s délkou follow-up pěti let [The results of five years follow-up prospective study of vaginal prolapse repaired by prolift total mesh surgery or sacrospinous fixation]. Ceska Gynekol 2017; 82: 277-86.

16. FDA. Urogynecologic Surgical Mesh: Update on the Safety and Effectiveness of Transvaginal Placement for Pelvic Organ Prolapse, 2011.https://www.fda.gov/downloads/MedicalDevices/Safety/ AlertsandNotices/UCM262760.pdf

17. Dirk G. Kieback. Bilateral Sacrospineous Colposuspension (BSC) in the treatment of vaginal vault prolapse - description of a novel method. Pelviperineology 2019; 38: 46-8. 